\title{
Hydroxyl accessibility in wood by deuterium exchange and ATR-FTIR spectroscopy: methodological uncertainties
}

\author{
Asghar Tarmian ${ }^{1} \cdot$ Ingo Burgert ${ }^{2,3} \cdot$ Emil Engelund Thybring $^{2,3,4}$ CD
}

Received: 9 September 2016/Published online: 13 May 2017

(C) Springer-Verlag Berlin Heidelberg 2017

\begin{abstract}
The accessibility of wood hydroxyls to water is commonly studied by infrared spectroscopy after deuteration where water-interacting hydroxyls have their $\mathrm{H}$ exchanged for D. In this study, the hydroxyl accessibility is determined with ATR-FTIR spectroscopy after deuteration of specimens with liquid $\mathrm{D}_{2} \mathrm{O}$. Several factors are examined to reveal the uncertainties involved in the accessibility determination. Despite the fact that specimens were able to interact with water vapour after deuteration and drying, producing a freshly cut surface just before measurement limited the effect of re-exchange of hydroxyls and gave for most batches reproducible results.
\end{abstract}

\section{Introduction}

The hygroscopicity of wood is a result of the capability of its chemical constituents to interact with water and form hydrogen bonds (H-bonds). A common way of investigating the accessibility of functional groups interacting with water is by deuteration (Altaner et al. 2006; Chow 1972; Fackler and Schwanninger 2011; Fernandes et al. 2011; Kontturi and Vuorinen 2009; Rautkari et al. 2013; Suchy 2011; Suchy et al. 2010a, b; Taniguchi et al. 1966, 1978; Thybring et al. 2017),

Emil Engelund Thybring

eet@ign.ku.dk

1 Faculty of Natural Resources, Department of Wood and Paper Science and Technology, University of Tehran, Tehran, Iran

2 Department of Civil, Environmental and Geomatic Engineering (D-BAUG), Institute for Building Materials, Wood Materials Science Group, ETH Zürich, Zurich, Switzerland

3 Applied Wood Materials, EMPA, Dübendorf, Switzerland

4 Department of Geosciences and Natural Resource Management, University of Copenhagen, Frederiksberg, Denmark 
whereby exposure to vast amounts of heavy water (deuterium oxide, $\mathrm{D}_{2} \mathrm{O}$ ) causes an $\mathrm{H}$-to-D exchange of all accessible functional groups capable of forming $\mathrm{H}$-bonds with the water (Englander et al. 1972). The result of the exchange can afterwards be measured either gravimetrically as an increase in dry mass or spectroscopically by significant changes $\left(\Delta \omega\right.$ around 1000,900 , and $800 \mathrm{~cm}^{-1}$ for $\mathrm{O}-\mathrm{H}, \mathrm{N}-\mathrm{H}$ and $\mathrm{C}-\mathrm{H}$ stretching vibrations, respectively, after deuteration) in vibrational frequency of exchanged groups (Gold and Satchell 1955). The latter technique is in focus in the current study which investigates uncertainties in the spectroscopic determination of water accessibility to functional groups in untreated wood.

The main functional groups within wood cell walls interacting with water are hydroxyls. This is seen by infrared spectroscopy after deuteration where only deuterated $\mathrm{O}-\mathrm{H}$ stretching vibrations are seen, whereas $\mathrm{C}-\mathrm{H}$ stretching vibrations remain unchanged and no deuterated $\mathrm{C}-\mathrm{H}$ vibrations can be found (Hofstetter et al. 2006; Mann and Marrinan 1956a; Schmidt et al. 2006; Taniguchi et al. 1966; Watanabe et al. 2006). Therefore, by focusing on the OD and OH stretching peaks and assuming that Beer's law holds, the relative hydroxyl accessibility can be determined as the ratio of areas of OD to OD + OH (Suchy et al. 2010b; Taniguchi et al. 1966) or alternatively by the ratio of weighted intensities of $\mathrm{OH}$ and OD peaks (Mann and Marrinan 1956b; Sepall and Mason 1961). The hydroxyl accessibility for wood is less than $100 \%$ as a large fraction of hydroxyl are confined within the compact, aggregated cellulose microfibrils and are inaccessible to water under normal conditions (Hofstetter et al. 2006; Salmén and Bergström 2009). This is evident from previous experimental studies of spectroscopically determined hydroxyl accessibility for various wood species, see Table 1. However, the true relative hydroxyl accessibility can be expected to differ from the experimentally derived result because of differences in specific vibrational intensity of OH and OD. Thus, it is not necessarily true that a given concentration of hydroxyls has the same vibrational intensity after full deuteration (Crawford 1952; Mann and Marrinan 1956b). For instance, cellulose and starch hydroxyl stretching vibrations were found to be about $10 \%$ more intense after deuteration (Mann and Marrinan 1956b; Nara et al. 1981), while the intensity is theoretically expected to be lower (Crawford 1952; Swenson 1965) as reported for wood with 10\% lower intensity (Chow 1972)

Table 1 Relative hydroxyl accessibility determined spectroscopically after deuteration

\begin{tabular}{lll}
\hline Wood species & Hydroxyl accessibility [\%] & References \\
\hline Japanese red pine & 42 & Taniguchi et al. (1966) \\
Norway spruce & 36 & Fackler and Schwanninger (2011) \\
Norway spruce & $40-44$ & Thybring et al. (2017) \\
Sitka spruce & 43 & Altaner et al. (2006) \\
Sitka spruce & 45 & Fernandes et al. (2011) \\
Douglas fir & $24-45$ & Chow (1972) \\
Japanese cypress & 47 & Taniguchi et al. (1966) \\
\hline
\end{tabular}


and as seen for liquid water, where the hydroxyl stretching vibration intensity is $29 \%$ lower for deuterated water (Venyaminov and Prendergast 1997). While the previous results suggest a higher true value for the experimentally determined hydroxyl accessibility, the latter result suggests a lower true value. Until this issue has been resolved for lignocellulosic materials, it remains uncertain whether the spectroscopic method can yield quantitative results for wood.

In this study, it is investigated how the handling of dry, deuterated wood specimens under laboratory conditions affects the spectroscopically determined hydroxyl accessibility.

\section{Materials and methods}

\section{Material}

Wood blocks of beech (Fagus sylvatica L.), Norway spruce (Picea abies L.) and Scots pine sapwood and heartwood (Pinus sylvestris L.), from trees grown in Switzerland, were cut with a sharp razor blade into specimens of dimensions $15 \times 10 \times 3 \mathrm{~mm}^{3}(L \times R \times T)$. Furthermore, Norway spruce specimens were also produced with dimensions $15 \times 10 \times 1,15 \times 10 \times 10^{3}$ and $30 \times 10 \times 3 \mathrm{~mm}^{3}$ $(L \times R \times T)$ to investigate the effect of specimen thickness and length. All batches contained seven replicates except for those two, related to specimen length which only contained three replicates.

\section{Deuteration in liquid $\mathrm{D}_{2} \mathrm{O}$}

Specimens were initially dried under vacuum $\left(60{ }^{\circ} \mathrm{C}, 0 \mathrm{mbar}, 24 \mathrm{~h}\right)$ followed by vacuum impregnation with $\mathrm{D}_{2} \mathrm{O}$. The latter was done by evacuating a reaction flask containing the specimens for $30 \mathrm{~min}$ and then injecting with a syringe through a rubber cork $40 \mathrm{~mL}$ liquid $\mathrm{D}_{2} \mathrm{O}$ (99.9 atom\% D, Sigma-Aldrich 1/2 GmbH, Buchs, Switzerland) per about $3.15 \mathrm{~cm}^{3}$ (about 1.2-1.5 g) wood under continuous vacuum pumping. Given that wood contains roughly 7-9 mmol hydroxyls per gram wood (Phuong et al. 2007; Popescu et al. 2014; Sumi et al. 1964; Thybring et al. 2017), the ratio of hydroxyls to deuterium supplied by liquid $\mathrm{D}_{2} \mathrm{O}$ is around 1:500. Hereafter, the specimens were left at saturated vapour pressure for $60 \mathrm{~min}$ before atmospheric pressure was re-established with dry nitrogen gas. After 120 min under these conditions, the liquid $\mathrm{D}_{2} \mathrm{O}$ was exchanged with a fresh batch of $40 \mathrm{~mL} \mathrm{D}_{2} \mathrm{O}$, the reaction flask flushed with dry nitrogen gas and closed for overnight deuteration (24 h in total). Finally, the specimens were dried in vacuum $\left(60{ }^{\circ} \mathrm{C}, 0 \mathrm{mbar}, 24 \mathrm{~h}\right)$, after which the atmospheric pressure was re-established using dry nitrogen gas. Specimens were then transferred to individual glass containers with desiccant (molecular sieves $3 \AA$, Sigma-Aldrich Chemie GmbH, Buchs, Switzerland) before being transported to the infrared spectrometer. For two batches of $15 \times 10 \times 3 \mathrm{~mm}^{3}$ Norway spruce specimens, the time in liquid $\mathrm{D}_{2} \mathrm{O}$ was increased to 48 and $72 \mathrm{~h}$, respectively, to study the effect of deuteration time. 


\section{Infrared spectroscopic measurements}

The infrared spectrum of each specimen was recorded with a Bruker Tensor 27 ATR-FTIR spectrometer (Bruker Optik GmbH, Fällanden, Switzerland) in the spectral range $4000-400 \mathrm{~cm}^{-1}$ with a resolution of $4 \mathrm{~cm}^{-1}$ using 64 scans with a total duration of $60 \mathrm{~s}$. Prior to each measurement, the specimen was split approximately in the middle along the LR plane with a sharp razor blade. The freshly cut surface was then quickly put on the diamond ATR crystal and the infrared spectrum recorded. All acquired IR spectra were analysed using OPUS version 7.2 software (Bruker Optik GmbH, Fällanden, Switzerland). Spectra were baseline-corrected using the concave rubber band method (ten iterations, 64 baseline points) and max-min normalised. To avoid contributions from $\mathrm{CO}_{2}$ vibrations (2300-2400 $\mathrm{cm}^{-1}$ ) in the spectra, only half the OD peak area (from $2700 \mathrm{~cm}^{-1}$ to peak height around $2500 \mathrm{~cm}^{-1}$ ) was calculated by numerical integration, see Fig. 1. For two series of $15 \times 10 \times 3 \mathrm{~mm}^{3}$ Norway spruce specimens, the effect of splitting and time before measurement was examined by either not splitting or letting the split specimens be exposed to laboratory conditions (app. 50\% RH, 22-24 ${ }^{\circ} \mathrm{C}$ ) for various amounts of time before the spectrum was recorded.

\section{Results and discussion}

Table 2 sums up the results for the five major experimental series examining different factors which affected the spectroscopically determined hydroxyl accessibility. Due to loss of specimens during the experiments, for example by

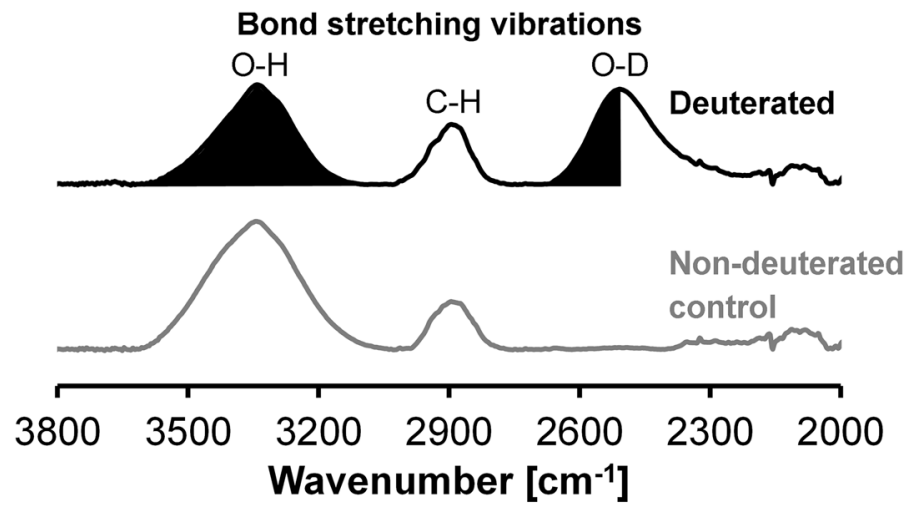

Fig. 1 Average ATR-FTIR spectrum in the range $2000-3800 \mathrm{~cm}^{-1}$ of deuterated Norway spruce after exposure to liquid $\mathrm{D}_{2} \mathrm{O}$ and vacuum drying. The black part of the $\mathrm{O}-\mathrm{H}$ and $\mathrm{O}-\mathrm{D}$ peaks illustrate the areas used for calculating the relative hydroxyl accessibility. Only the area between $2700 \mathrm{~cm}^{-1}$ and O-D peak height wavenumber (around $2510 \mathrm{~cm}^{-1}$ ) was determined to avoid contributions from $\mathrm{CO}_{2}$ vibrations in the $2300-2400 \mathrm{~cm}^{-1}$ range. The determined half O-D peak area was then doubled for accessibility determinations. Also shown in grey is an example of a spectrum of non-deuterated Norway spruce in the range $2000-3800 \mathrm{~cm}^{-1}$ 
Table 2 Spectroscopically determined hydroxyl accessibility for different, untreated wood species and specimen sizes

\begin{tabular}{|c|c|c|c|c|c|}
\hline Series & $\begin{array}{l}\text { Wood } \\
\text { specimens }\end{array}$ & $\begin{array}{l}\text { Specimen } \\
\text { size }\end{array}$ & $\begin{array}{l}\text { Deuteration } \\
\text { time }[\mathrm{h}]\end{array}$ & $\begin{array}{l}\text { Batch } \\
\text { size }\end{array}$ & $\begin{array}{l}\text { Hydroxyl } \\
\text { accessibility } \\
{[\%]}\end{array}$ \\
\hline \multirow[t]{2}{*}{ 1. Splitting } & Norway spruce, split & $15 \times 10 \times 3 \mathrm{~mm}$ & 24 & 7 & $33.4(6.0)^{\mathrm{c}}$ \\
\hline & $\begin{array}{l}\text { Norway spruce, not } \\
\text { split }\end{array}$ & $15 \times 10 \times 3 \mathrm{~mm}$ & 24 & 5 & $20.3(7.6)^{\mathrm{a}}$ \\
\hline \multirow{3}{*}{$\begin{array}{l}\text { 2. Deuteration } \\
\text { time }\end{array}$} & Norway spruce, split & $15 \times 10 \times 3 \mathrm{~mm}$ & 24 & 7 & $29.0(1.4)^{b}$ \\
\hline & Norway spruce, split & $15 \times 10 \times 3 \mathrm{~mm}$ & 48 & 6 & $33.4(3.5)^{\mathrm{c}}$ \\
\hline & Norway spruce, split & $15 \times 10 \times 3 \mathrm{~mm}$ & 72 & 7 & $33.4(3.3)^{\mathrm{c}}$ \\
\hline \multirow[t]{2}{*}{ 3. Length } & Norway spruce, split & $15 \times 10 \times 3 \mathrm{~mm}$ & 24 & 3 & $34.4(2.5)^{\mathrm{c}}$ \\
\hline & Norway spruce, split & $30 \times 10 \times 3 \mathrm{~mm}$ & 24 & 3 & $33.8(2.7)^{\mathrm{c}}$ \\
\hline \multirow[t]{3}{*}{ 4. Thickness } & Norway spruce, split & $15 \times 10 \times 1 \mathrm{~mm}$ & 24 & 7 & $21.0(2.3)^{\mathrm{a}}$ \\
\hline & Norway spruce, split & $15 \times 10 \times 3 \mathrm{~mm}$ & 24 & 6 & $37.8(1.8)^{\mathrm{c}, \mathrm{d}, \mathrm{e}}$ \\
\hline & Norway spruce, split & $15 \times 10 \times 10 \mathrm{~mm}$ & 24 & 4 & $35.0(1.1)^{\mathrm{c}}$ \\
\hline \multirow[t]{4}{*}{ 5. Species } & Beech, split & $15 \times 10 \times 3 \mathrm{~mm}$ & 24 & 5 & $37.5(6.7)^{\mathrm{c}, \mathrm{d}}$ \\
\hline & Pine sapwood, split & $15 \times 10 \times 3 \mathrm{~mm}$ & 24 & 7 & $41.6(5.4)^{\mathrm{e}, \mathrm{f}}$ \\
\hline & Pine heartwood, split & $15 \times 10 \times 3 \mathrm{~mm}$ & 24 & 7 & $39.9(6.9)^{\mathrm{d}}$ \\
\hline & Norway spruce, split & $15 \times 10 \times 3 \mathrm{~mm}$ & 24 & 6 & $44.3(4.0)^{f}$ \\
\hline
\end{tabular}

Batches which are not statistically significantly different $(\alpha=5 \%)$ based on Duncan's multiple range test have been grouped with similar letters

Highlighted in bold are five seemingly identical batches and their accessibilities

uncontrolled breaking during splitting, or too low infrared signal intensity because of inadequate mechanical force pushing the specimen to the ATR crystals, some batches contain less replicates than previously specified. The data for the remaining replicates appear to be in line with previous findings. Thus, the results for Norway spruce are in line with the 36-44\% hydroxyl accessibility reported in the literature (Table 1), except for those with the shortest deuteration time in series 2 and the thinnest specimens in series 4 . The first of these batches appears to be an outlier, since the four other similar batches highlighted in bold in Table 2 yield significantly higher accessibilities. Thus, it seems that the standard deuteration protocol employed in this study was able to fully deuterate accessible hydroxyls as the accessibility would have otherwise been seen to increase with deuteration time in series 2 .

One main concern with the spectroscopic methodology described in this study is water sorption in the time between deuteration and until the infrared spectrum is recorded. This can be avoided when the drying of wet, deuterated specimens is performed in the spectroscopic equipment in a dry purge gas (Altaner et al. 2006; Fackler et al. 2011). However, in the current study specimens are handled in laboratory conditions after vacuum drying. Thus, when specimens are taken out of the vacuum oven and transferred to the spectrometer, water molecules in the surrounding air may be adsorbed by the wood and interact with deuterated hydroxyls. This will cause a decrease in the determined hydroxyl accessibility both 
due to re-protonation of hydroxyls, i.e. exchange of $\mathrm{D}-\mathrm{H}$, and due to an increase in $\mathrm{O}-\mathrm{H}$ vibrations from adsorbed water molecules. Splitting of deuterated specimens limits the effect of handling time between vacuum drying and spectrometry by producing a fresh, inner wood surface right before infrared measurements. Thus, it is clear from series 1 that even swift handling of specimens after drying markedly decreases the determined accessibility of non-split specimens. Similarly, Fig. 2 illustrates the determined accessibility of a batch with specimens exposed to laboratory conditions for up to $60 \mathrm{~min}$ after splitting. After $10 \mathrm{~min}$ of exposure, the accessibility is $30 \%$ lower than for the specimen immediately transferred to the spectrometer after splitting.

The risk of re-protonation also plays a role in the recommended specimen geometry. In this study, specimens of $1 \mathrm{~mm}$ thickness yielded lower hydroxyl accessibility than specimens of 3 or $10 \mathrm{~mm}$ thickness but similar to that of the nonsplit batch. Increasing the length from 15 to $30 \mathrm{~mm}$ did not yield any difference in accessibility. This indicates that the cut surface of 1-mm-thick specimens after splitting may have interacted with water during handling due to the short transport path into the specimen. Moreover, it should be noted that satisfactory splitting in the middle of the specimen is difficult if this is either too small (1 mm thick) or too large (10 $\mathrm{mm}$ thick or $30 \mathrm{~mm}$ long).

The three wood species examined in this study did show some differences as seen from the grouping in Table 2 based on Duncan's multiple range test. Thus, beech and pine heartwood yielded slightly lower hydroxyl accessibility than pine sapwood and Norway spruce. It is unclear whether this is due to fewer hydroxyls present in beech hemicelluloses (Teleman et al. 2002) than in spruce (Sjöström 1993) and the presence of extractives in pine heartwood. It should, however, be noted that the standard deviation was unexplainably higher in series 1 and 5 than in the other experimental series. No other published studies have examined beech and pine, but

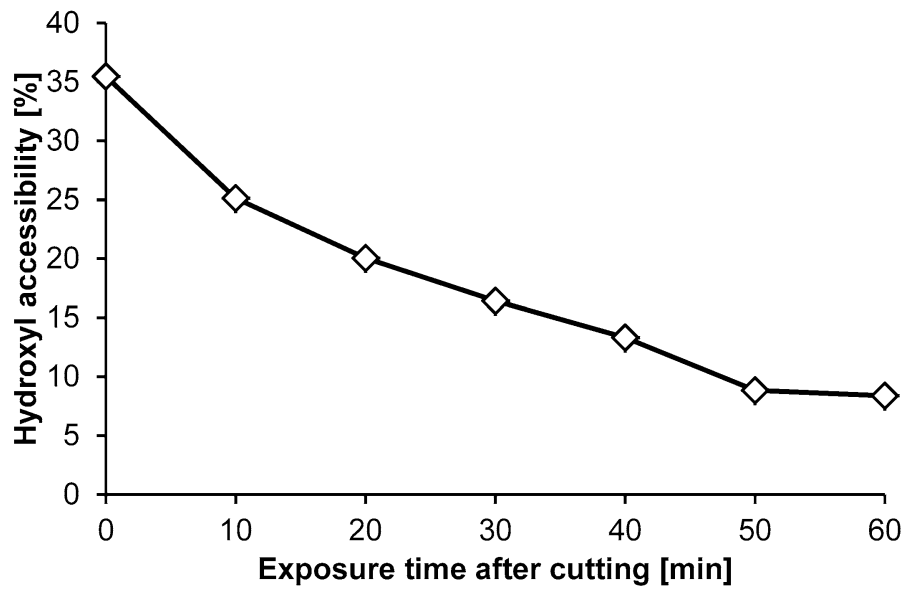

Fig. 2 Spectroscopically determined hydroxyl accessibility for one series of $15 \times 10 \times 3 \mathrm{~mm}^{3}$ specimens of Norway spruce at different times of exposure to laboratory conditions after splitting in the middle 


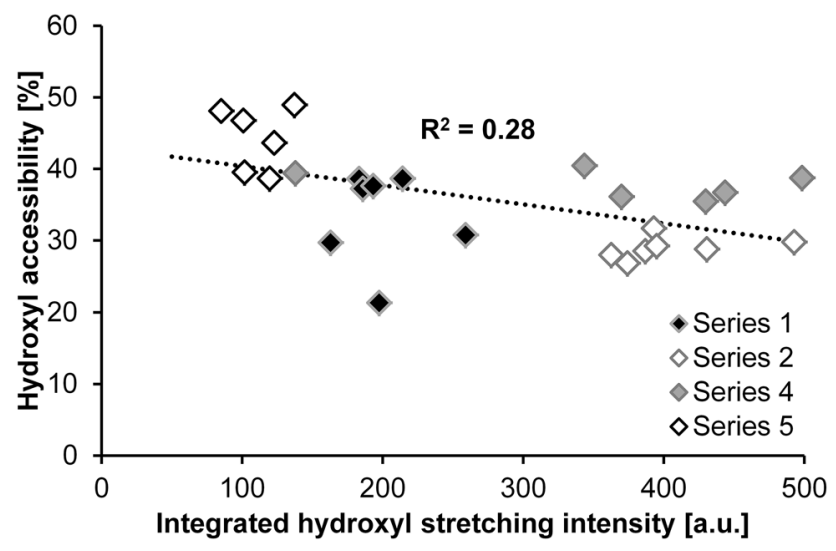

Fig. 3 Relation between spectroscopically determined hydroxyl accessibility and integrated vibrational intensity of hydroxyls (both $\mathrm{OH}$ and OD) in deuterated $15 \times 10 \times 3 \mathrm{~mm}^{3}$ specimens of Norway spruce from four different experimental series

the accessibility determined in this study is within the variability seen for other wood species examined in the literature (Table 1).

One factor which is difficult to control accurately with the ATR-FTIR equipment used in this study is the clamping force used to push the specimen against the ATR crystal. The signal intensity of a given vibration varies with clamping force. However, the ratio between peaks is quite constant for various force levels (Spragg 2011). Thus, after baseline correction and normalisation, the vibrational intensity of the different bonds should be quite similar. Therefore, it is expected that the determined hydroxyl accessibility by ratios of peak areas should be similarly insensitive to clamping force. This can be indirectly seen from the poor correlation in Fig. 3, which shows the relation between determined hydroxyl accessibility and total peak area of hydroxyls (both $\mathrm{OH}$ and $\mathrm{OD}$ vibrations) for four similar batches. Therefore, differences in hydroxyl accessibility between batches of similarly treated Norway spruce specimens highlighted in bold in Table 2 cannot be explained from variation in clamping force. Differences in annual ring width and thus early-/latewood ratio might explain it, as Chow (1972) found earlywood in Douglas fir to have considerably lower relative hydroxyl accessibility than latewood of the same species. This topic has, however, not been explored further in other studies.

\section{Conclusion}

This study illustrates some of the uncertainties involved with the infrared spectroscopically determined hydroxyl accessibility of wood after deuterium exchange. In particular, the risk of re-protonation of deuterated hydroxyls in dry wood specimens during handling is highlighted. Splitting of specimens with adequate dimensions (thickness of at least $3 \mathrm{~mm}$ ) was shown to give similar 
hydroxyl accessibilities for most specimen batches. However, for some of these the determined accessibility deviated inexplicably from the others and results from the literature.

Acknowledgements EET gratefully acknowledges financial support from FP7: People Marie-Curie action COFUND (EMPA POSTDOCS, Project No. 267161).

\section{References}

Altaner C, Apperley DC, Jarvis MC (2006) Spatial relationships between polymers in sitka spruce: proton spin-diffusion studies. Holzforschung 60:665-673

Chow SZ (1972) Hydroxyl accessibility, moisture-content, and biochemical activity in cell-walls of douglas-fir trees. Tappi 55:539-544

Crawford B (1952) Vibrational intensities II. The use of isotopes. J Chem Phys 20:977-981

Englander SW, Downer NW, Teitelbaum H (1972) Hydrogen-exchange. Annu Rev Biochem 41:903-924

Fackler K, Schwanninger M (2011) Accessibility of hydroxyl groups of brown-rot degraded spruce wood to heavy water. J Near Infrared Spec 19:359-368

Fackler K, Stevanic JS, Ters T, Hinterstoisser B, Schwanninger M, Salmén L (2011) FT-IR imaging microscopy to localise and characterise simultaneous and selective white-rot decay within spruce wood cells. Holzforschung 65:411-420

Fernandes AN, Thomas LH, Altaner CM, Callow P, Forsyth VT, Apperley DC, Kennedy CJ, Jarvis MC (2011) Nanostructure of cellulose microfibrils in spruce wood. Proc Natl Acad Sci USA 108:E1195E1203

Gold V, Satchell DPN (1955) The principles of hydrogen isotope exchange reactions in solution. Q Rev Chem Soc 9:51-72

Hofstetter K, Hinterstoisser B, Salmén L (2006) Moisture uptake in native cellulose-the roles of different hydrogen bonds: a dynamic FT-IR study using deuterium exchange. Cellulose 13:131-145

Kontturi E, Vuorinen T (2009) Indirect evidence of supramolecular changes within cellulose microfibrils of chemical pulp fibers upon drying. Cellulose 16:65-74

Mann J, Marrinan HJ (1956a) The reaction between cellulose and heavy water 1. A qualitative study by infra-red spectroscopy. T Faraday Soc 52:481-487

Mann J, Marrinan HJ (1956b) The reaction between cellulose and heavy water 3. A quantitative study by infra-red spectroscopy. T Faraday Soc 52:492-497

Nara S, Takeo H, Komiya T (1981) Studies on the accessibility of starch by deuteration. Starch-Stärke 33:329-331

Phuong LX, Takayama M, Shida S, Matsumoto Y, Aoyagi T (2007) Determination of the accessible hydroxyl groups in heat-treated styrax tonkinensis (Pierre) craib ex hartwich wood by hydrogendeuterium exchange and H-2 NMR spectroscopy. Holzforschung 61:488-491

Popescu CM, Hill CAS, Curling S, Ormondroyd GA, Xie Y (2014) The water vapour sorption behaviour of acetylated birch wood: how acetylation affects the sorption isotherm and accessible hydroxyl content. J Mater Sci 49:2362-2371

Rautkari L, Hill CAS, Curling S, Jalaludin Z, Ormondroyd GA (2013) What is the role of the accessibility of wood hydroxyl groups in controlling moisture content? J Mater Sci 48:6352-6356

Salmén L, Bergström E (2009) Cellulose structural arrangement in relation to spectral changes in tensile loading FTIR. Cellulose 16:975-982

Schmidt M, Gierlinger N, Schade U, Rogge T, Grunze M (2006) Polarized infrared microspectroscopy of single spruce fibers: hydrogen bonding in wood polymers. Biopolymers 83:546-555

Sepall O, Mason SG (1961) Hydrogen exchange between cellulose and water 1. Measurement Access Can J Chem 39:1934-1943

Sjöström E (1993) Wood polysaccharides. In: Sjöström E (ed) Wood Chemistry, 2nd edn. Academic Press, San Diego, pp 51-70

Spragg R (2011) Contact and orientation effects in FT-IR ATR spectra. Spectroscopy 26:digital

Suchy M (2011) Accessibility and enzymatic degradation of native and model cellulose substrates, PhD thesis, Aalto University, Espoo, Finland 
Suchy M, Kontturi E, Vuorinen T (2010a) Impact of drying on wood ultrastructure: similarities in cell wall alteration between native wood and isolated wood-based fibers. Biomacromol 11:2161-2168

Suchy M, Virtanen J, Kontturi E, Vuorinen T (2010b) Impact of drying on wood ultrastructure observed by deuterium exchange and photoacoustic FT-IR spectroscopy. Biomacromol 11:515-520

Sumi Y, Hale RD, Meyer JA, Leopold B, Rånby BG (1964) Accessibility of wood and wood carbohydrates measured with tritiated water. Tappi 47:621-624

Swenson CA (1965) Absolute infrared intensities of HDO in aqueous solution. Spectrochim Acta 21:987-993

Taniguchi T, Harada H, Nakato K (1966) Accessibility of hydroxyl groups in wood. Mokuzai Gakkaishi 10:215-220

Taniguchi T, Harada H, Nakato K (1978) Determination of water-adsorption sites in wood by a hydrogendeuterium exchange. Nature 272:230-231

Teleman A, Tenkanen M, Jacobs A, Dahlman O (2002) Characterization of O-acetyl-(4-O-methylglucurono)xylan isolated from birch and beech. Carbohyd Res 337:373-377

Thybring EE, Thygesen LG, Burgert I (2017) Hydroxyl accessibility in wood cell walls as affected by drying and re-wetting procedures. Cellulose 24:2375-2384

Venyaminov SY, Prendergast FG (1997) Water $\left(\mathrm{H}_{2} \mathrm{O}\right.$ and $\left.\mathrm{D}_{2} \mathrm{O}\right)$ molar absorptivity in the $1000-4000 \mathrm{~cm}^{-1}$ range and quantitative infrared spectroscopy of aqueous solutions. Anal Biochem 248:234-245

Watanabe A, Morita S, Kokot S, Matsubara M, Fukai K, Ozaki Y (2006) Drying process of microcrystalline cellulose studied by attenuated total reflection IR spectroscopy with twodimensional correlation spectroscopy and principal component analysis. J Mol Struct 799:102-110 